Purdue University

Purdue e-Pubs

CTRC Research Publications

Cooling Technologies Research Center

2012

\title{
Second-Law Analysis of Molten-Salt Thermal Energy Storage in Thermoclines
}

\author{
S. Flueckiger \\ Purdue University \\ S V. Garimella \\ Purdue University, sureshg@purdue.edu
}

Follow this and additional works at: http://docs.lib.purdue.edu/coolingpubs

Flueckiger, S. and Garimella, S V., "Second-Law Analysis of Molten-Salt Thermal Energy Storage in Thermoclines" (2012). CTRC Research Publications. Paper 176.

http://dx.doi.org/http://dx.doi.org/10.1016/j.solener.2012.02.028

This document has been made available through Purdue e-Pubs, a service of the Purdue University Libraries. Please contact epubs@purdue.edu for additional information. 


\title{
Second-Law Analysis of Molten-Salt Thermal Energy Storage in Thermoclines*
}

\author{
Scott M. Flueckiger and Suresh V. Garimella** \\ School of Mechanical Engineering \\ 585 Purdue Mall, Purdue University \\ West Lafayette, IN 47907-2088 USA
}

* Revised for publication in Solar Energy, October 2011, and in revised form, January 2012

** Author to whom correspondence should be addressed: (765) 494-5621, sureshg@ @urdue.edu 


\section{Abstract}

The cyclic operation of a molten-salt thermocline tank is simulated to investigate the influence of internal granule diameter and external convection losses on tank performance. Practical constraints limiting thermocline tank height are taken into account. The authors twotemperature model, developed in earlier work (Solar Energy 84:974-985, 2010) for the analysis of heat transfer and fluid flow in the thermocline tank, is extended to monitor entropy generation and exergy transport. Storage performance is measured in terms of first- and second-law efficiency definitions, as well as a first-law efficiency used in conjunction with an outflow temperature criterion. Reducing the diameter of the fillerbed granules improves the thermocline tank performance by sustaining higher molten-salt outflow temperatures throughout the discharge phase of the cycle, which results in greater operational efficiency. External convection losses strongly influence entropy generation inside the tank fillerbed due to the development of radial temperature gradients and increased irreversible thermal diffusion. Convection losses also result in lower tank efficiencies due to the reduction of hot molten salt available inside the tank. A comparison of the different efficiency definitions employed in this work reveal that the $a d$ hoc outflow temperature criterion used in past studies provides an overly conservative assessment of thermocline performance.

Keywords: solar thermal energy, thermocline, molten salt, exergy 


\section{Introduction}

Diminishing fossil-fuel reserves and accelerating anthropogenic climate change via greenhouse gas emissions have renewed global interest in the conversion of solar energy to electricity. Large-scale conversion is possible with concentrating solar power (CSP) plants which focus sunlight via heliostats, parabolic troughs, or Fresnel reflectors (Kolb et al., 1991; Mills and Morrison, 2000) onto a tubing network carrying a heat transfer fluid (HTF). The HTF captures the incident radiation as sensible heat that is then supplied to a steam boiler within a Rankine power cycle. CSP technologies have been demonstrated at both experimental and commercial scales, but remain subject to variations in available sunlight due to cloud transients, planetary rotation, and seasonal changes. The effects act at multiple time scales to diminish plant performance and limit the overall reliability of electricity generation from the plant. To match the reliability of fossil-fired and nuclear power plants, the CSP plant must be augmented with either auxiliary fossil fuel supplies or reserves of excess energy collected and stored during periods of high solar irradiance. Fossil-fuel backup is undesirable due to the inherent environmental impact. In contrast, energy storage decouples the power cycle from the collection system via sufficient reserves of useful energy to offset periodic losses in sunlight.

Energy storage has been studied for CSP applications with sensible heat, latent heat, and thermochemical reactions (Herrmann and Kearney, 2002; Lovegrove et al., 2004). Of these methods, sensible heat storage in an excess volume of HTF is preferred due to simplicity and low relative cost. During periods of high irradiance, excess HTF heated in the collection loop is diverted to a storage volume for later use. Thermocline tanks offer a low-cost means of realizing this concept by storing both the hot and cold fluid inside a single reservoir. Buoyancy forces, associated with the variation of the HTF density with temperature, maintain stable thermal 
stratification of the two isothermal volumes. A narrow region of large temperature gradient exists at the interface of these fluid volumes, known as the thermocline or heat-exchange region. The vertical location of this heat-exchange region varies in time as the hot HTF is added and then extracted. Cyclic operation of the thermocline tank requires flow reversal in order to maintain the thermal stratification (fluid flow is downward to charge the tank with hot HTF and subsequently upward to discharge the hot HTF). When the heat-exchange region reaches the top of the fillerbed, the hot supply of HTF is exhausted and the power cycle is no longer supported by the storage system. Such a tank offers significant financial advantages over an alternative two-tank implementation (Kearney et al., 2003; Electric Power Research Institute, 2010).

Constraints related to practical delivery of heat to the steam boiler restrict the selection of HTF to materials that remain liquid at very high temperatures, i.e., synthetic oils and molten salts. Synthetic oils are an expedient design option as they remain in liquid phase under ambient conditions. However, low vapor pressures limit operation of oils to temperature below $400{ }^{\circ} \mathrm{C}$, a significant constraint on the CSP plant thermal efficiency. Significant gains in efficiency are possible with a transition to molten nitrate-salt mixtures, which remain liquid up to $600{ }^{\circ} \mathrm{C}$. Furthermore, molten salts are low-cost, non-flammable, and non-toxic. Commercial salt mixtures include solar salt (40 wt $\% \mathrm{KNO}_{3}, 60 \mathrm{wt} \% \mathrm{NaNO}_{3}$ ) and $\mathrm{HITEC}\left(35 \mathrm{wt} \% \mathrm{KNO}_{3}, 40 \mathrm{wt} \% \mathrm{NaNO}_{2}\right.$, $7 \mathrm{wt} \% \mathrm{NaNO}_{3}$, Coastal Chemical Co.). Both mixtures are eutectics and have melting points above ambient; HITEC exhibits a liquid operation range of $142{ }^{\circ} \mathrm{C}$ to $535{ }^{\circ} \mathrm{C}$ (Kearney et al., 2003). Freeze prevention and recovery is essential in all salt-based systems to maintain the salt at elevated temperatures and to minimize component damage in the event of a change of phase.

In addition to the HTF, the interior of the thermocline tank is filled with a low-cost filler material to act as an additional storage medium and to reduce the required volume of the more 
expensive salt. Granulating the filler material inhibits thermal diffusion in the axial tank direction, maintaining thermal stratification in the surrounding fluid. The resultant porous assembly is termed a dual-media thermocline tank. Selection of the filler material is not trivial as repeated thermal cycling of the tank may lead to degradation of the granules and potential entrainment into the fluid flow. Pacheco et al. (2002) screened several candidate materials for use in molten-salt thermoclines through prolonged exposure to salt at different thermal conditions. Quartzite rock and silica sand were found to be the most resistant to degradation after several hundred thermal cycles.

The dual-media thermocline thermal storage concept was first demonstrated with a 170 $\mathrm{MWh}_{\mathrm{t}}$ tank in conjunction with the Solar One pilot central-receiver plant in Barstow, CA (Faas et al., 1986; Radosevich, 1988). The tank interior consisted of Caloria mineral oil as the HTF, granite rock as the solid filler, and ullage space filled nitrogen. While in operation from 1982 to 1986, temperature limitations of the Caloria, coupled with insufficient heliostats in the collection field for excess solar energy capture, relegated the thermocline tank to auxiliary steam generation. Pacheco et al. (2002) later constructed a small-scale 2.3 $\mathrm{MWh}_{\mathrm{t}}$ thermocline at Sandia National Laboratories to validate the use of molten salt with quartzite rock and silica sand. A thermocouple rake imbedded in the tank indicated successful thermal stratification of the salt.

The geometric size and high operating temperature associated with physical tanks have largely limited analysis of the thermocline concept to numerical simulation. Kolb (2006) developed a CSP plant system model using TRNSYS commercial software to simulate the theoretical addition of a $30 \mathrm{MWh}_{\mathrm{t}}$ thermocline tank to the $1 \mathrm{MW}$ Saguaro parabolic trough plant near Tucson, AZ. The thermocline tank was modeled in TRNSYS as a one-dimensional component with thermal losses enforced at the roof, floor, and surrounding wall. The 
performance of the thermocline model was validated against experimental data from the Solar One thermocline tank. The resultant system simulation revealed that thermocline storage in conjunction with an expanded heliostat field increased the capacity factor of the Saguaro plant from $23 \%$ to $42 \%$.

Yang and Garimella (2010a) developed a computational fluid dynamics model of a molten-salt thermocline tank to investigate multi-dimensional effects. Energy transport inside the tank was solved with a two-temperature model in order to account for the different transport properties of the fluid and solid. The performance of the model was validated with experimental tank data reported by Pacheco et al. (2002). The authors conducted a parametric study of tank size, granule diameter, and discharge power to determine optimum discharge conditions. Discharge performance improved with increased tank height and increased storage capacity. Performance also improved with decreased granule diameter and reduced discharge power, characterized by low interstitial Reynolds numbers.

Yang and Garimella (2010b) updated their model to include convection losses at the tank wall to the ambient surroundings. In contrast to the results obtained under adiabatic-wall conditions, the discharge performance of the thermocline decreased with low interstitial Reynolds numbers. At these low Reynolds numbers, the reduced fluid velocity increased the residence time of the molten salt inside the tank and prolonged cooling of salt near the tank wall. This phenomenon is less pertinent at larger Reynolds numbers for which the discharge performance better matched the equivalent adiabatic tank wall results.

Yang and Garimella (in review) extended the adiabatic model to study cyclic effects of the charge-discharge processes. As with the previous adiabatic discharge model, performance of the thermocline tank improved with increased tank height and decreased granule diameter. Cycle 
efficiencies associated with the thermocline models were curve-fit as a function of the interstitial Reynolds number and the ratio of molten-salt flow distance to the filler diameter. Flueckiger et al. (2011) updated this cyclic investigation to include effects of convection and radiation losses to the surroundings as well as a composite tank wall for analysis of thermal ratcheting as a potential failure mode.

In the parameter studies performed of Yang and Garimella (2010a; 2010b; in review), the model tank size varied over several fillerbed heights from $2.77 \mathrm{~m}$ to $56.7 \mathrm{~m}$ in order to construct the reported efficiency functions. Practical limits related to soil bearing capacity were not imposed on the tank height. A recent civil engineering study of Barstow, CA soil found that physical thermocline tanks should not exceed 39 feet $(11.9 \mathrm{~m})$ (Electric Power Research Institute, 2010). In addition, Yang and Garimella (2010a; 2010b; in review) measured thermocline tank performance solely on an energy (enthalpy) basis. The authors enforced an $a d$ hoc temperature cut-off criterion to the outflow molten-salt discharge to account for the loss of thermal quality. Only salt outflow at temperatures above $95 \%$ of the total operating range was designated as being useful for power production. For example, if the temperature difference between the hot and cold fluid states was $100 \mathrm{~K}$, only molten salt discharge within $5 \mathrm{~K}$ of the hot temperature limit was designated as usable for steam generation in the Rankine cycle.

An alternative approach to this ad hoc criterion is to measure the quality of the outflow using the thermodynamic definition of exergy. It is important to note that thermal energy storage devices must store not only energy, but also exergy (Bejan, 2006). Unlike energy, exergy is not subject to a conservation law and can be destroyed. This destruction is directly proportional to the generation of entropy associated with the second law of thermodynamics. In the present work, a numerical simulation of the dual-media thermocline tank is conducted to investigate 
entropy generation inside the fillerbed as well as the recovery of energy and exergy during cyclic operation. A parametric study of fillerbed granule diameter and external convection losses assesses the respective influence on both first- and second-law cycle efficiencies. These results are then compared to the outflow temperature criterion-based efficiency used in the literature.

\section{Numerical Modeling}

\subsection{Problem Description}

A schematic diagram of the thermocline storage tank is provided in Figure 1. The tank of diameter $d$ is filled with a porous bed of granulated filler to a height $h$. Adjacent to the top and bottom of the porous fillerbed are two distributors of height $h^{\prime}\left(h^{\prime}=0.05 h\right)$, free of any filler. Fluid enters and exits the tank through two tubular ports of diameter $d^{\prime}\left(d^{\prime}=0.1 d\right)$ extending from the distributors. The open distributor regions serve to diffuse the turbulent tube flow at the distributor inlet evenly into the tank fillerbed, preventing the formation of radial temperature gradients in the stratified fluid. An alternative form of distribution is though the use of pipe manifolds imbedded within the fillerbed. Such manifolds are not axisymmetric and drastically increase the computational resources necessary to model the thermocline tank. The open distributor regions considered here simplify the numerical approach and maintain axisymmetric flow conditions.

HITEC molten salt is selected as the thermocline tank heat transfer fluid. For thermal transport analysis, the specific heat $\left(C_{P, l}\right)$ of HITEC salt is $1561.7 \mathrm{~J} / \mathrm{kg} \mathrm{K}$. Temperaturedependent functions, derived by Yang and Garimella (2010a) from experimental data (Coastal Chemical Co.), provide the fluid density, viscosity, and thermal conductivity:

$$
\rho_{l}\left(T_{l}\right)=1938-0.732\left(T_{l}-200\right)
$$




$$
\begin{aligned}
& \mu\left(T_{l}\right)=\exp \left[-4.343-2.0143\left(\ln \left(T_{l}\right)-5.011\right)\right] \\
& k_{l}\left(T_{l}\right)=-6.53 \times 10^{-4}\left(T_{l}-260\right)+0.421
\end{aligned}
$$

The porosity of the solid filler is fixed at 0.22 in accordance with experimental observation for quartzite rock and silica sand mixture (Pacheco et al., 2002). To simplify analysis of the mixture, the size of the filler is defined with a single representative granule diameter. The density and specific heat are taken as quartzite rock properties, $830 \mathrm{~kg} / \mathrm{m}^{3}$ and $2500 \mathrm{~J} / \mathrm{kg} \mathrm{K}$ (Specific Heat Capacities of Some Common Substances). The solid thermal conductivity is derived from data for quartz materials (Heraeus Base Materials). However, thermal diffusion between solid granules is neglected in the model due to the small contact area and high contact resistance between particles. The solid granules still influence diffusion in the surrounding molten salt, characterized by the following correlation for effective thermal conductivity (Gonzo, 2002):

$$
k_{\text {eff }}=k_{l} \frac{1+2 \beta \phi+\left(2 \beta^{3}-0.1 \beta\right) \phi^{2}+\phi^{3} 0.05 \exp [4.5 \beta]}{1-\beta \phi}
$$

where $\phi=1-\varepsilon$ and $\beta=\left(k_{s}-k_{l}\right) /\left(k_{s}+2 k_{l}\right)$.

The velocity of the moving heat-exchange region is influenced by conduction and convection with the solid filler and is therefore not equal to the velocity of the molten-salt flow, but is also dependent on the porosity and volumetric heat capacities of the dual storage media. Yang and Garimella (in review) defined the ratio of the heat-exchange zone velocity to moltensalt superficial velocity $\left(C_{0}\right)$ as follows:

$$
C_{0}=\frac{v}{u_{0}}=\frac{\rho_{l, h} C_{P, l}}{\varepsilon \rho_{l, h} C_{P, l}+(1-\varepsilon) \rho_{s} C_{P, s}}
$$

For the properties of the chosen mixture of molten salt and rock, this velocity ratio is 1.23 .

\subsection{Governing Equations}


Governing equations for mass and momentum transport in the molten-salt fluid contained in the thermocline tank are as follows, with the momentum flux in the porous fillerbed being governed by Darcy's Law with the Brinkman-Forchheimer extension:

$$
\begin{aligned}
& \frac{\partial\left(\varepsilon \rho_{l}\right)}{\partial t}+\nabla \cdot\left(\rho_{l} \mathbf{u}\right)=0 \\
& \frac{\partial\left(\rho_{l} \mathbf{u}\right)}{\partial t}+\nabla \cdot\left(\rho_{l} \frac{\mathbf{u} \mathbf{u}}{\varepsilon}\right)=-\varepsilon \nabla P+\nabla \cdot \tilde{\boldsymbol{\tau}}+\varepsilon \rho_{l} \mathbf{g}-\varepsilon\left(\frac{\mu}{K} \mathbf{u}+\frac{F}{\sqrt{K}} \rho_{l}|\mathbf{u}| \mathbf{u}\right)
\end{aligned}
$$

In the momentum transport equation, the stress deviator tensor is defined as $\tilde{\boldsymbol{\tau}}=2 \mu \widetilde{\mathbf{S}}-\frac{2}{3} \mu \operatorname{tr}(\widetilde{\mathbf{S}})$, where $\widetilde{\mathbf{S}}=\frac{1}{2}\left(\nabla \mathbf{u}+(\nabla \mathbf{u})^{T}\right)$ is the rate of strain tensor. The spatial gradient of the thermocline tank in polar coordinates is $\nabla=\mathbf{e}_{\mathbf{r}} \frac{\partial}{\partial r}+\frac{\mathbf{e}_{\theta}}{r} \frac{\partial}{\partial \theta}+\mathbf{e}_{x} \frac{\partial}{\partial x}$. The axisymmetric nature of the thermocline geometry eliminates all velocities and functional dependencies in the circumferential direction $(\theta)$. The inertial coefficient $(F)$ and permeability $(K)$ are determined from the literature (Krishnan et al., 2004; Beckermann and Viskanta, 1988).

Separate energy equations for the molten salt (subscripted $l$ ) and filler (subscripted $s$ ) are required to model non-thermal-equilibrium conditions between the fluid and solid:

$$
\begin{aligned}
& \frac{\partial\left(\varepsilon \rho_{l} C_{P, l} T_{l}\right)}{\partial t}+\nabla \cdot\left(\rho_{l} \mathbf{u} C_{P, l} T_{l}\right)=\nabla \cdot\left(k_{e f f} \nabla T_{l}\right)+\mu \Phi+h_{i}\left(T_{s}-T_{l}\right) \\
& \frac{\partial\left((1-\varepsilon) \rho_{s} C_{P, s} T_{s}\right)}{\partial t}=-h_{i}\left(T_{s}-T_{l}\right)
\end{aligned}
$$

Equations (8) and (9) remain coupled by a volumetric heat transfer coefficient $\left(h_{i}\right)$ associated with convective heat exchange between the molten salt and solid filler. Interstitial forced convection in the porous media is modeled with the Wakao and Kaguei (1982) correlation:

$$
\mathrm{Nu}_{i}=6(1-\varepsilon)\left(2+1.1 \operatorname{Re}^{0.6} \operatorname{Pr}^{1 / 3}\right)
$$


Thermal diffusion in the fillerbed is enforced only in the fluid energy equation via the effective thermal conductivity of the dual-media mixture. As noted before, thermal diffusion is neglected in the solid filler due to contact resistance between particles. Non-dimensional terms associated with the geometry and molten-salt flow inside the fillerbed are defined as: $X=\frac{x}{u_{0} t_{0}}, R=\frac{r}{u_{0} t_{0}}$, $\Psi=\frac{u_{0} t_{0}}{d_{s}}, \tau=\frac{t}{t_{0}}, \Theta=\frac{T_{l}-T_{c}}{T_{h}-T_{c}}, \operatorname{Re}=\frac{\rho_{l} u_{0} d_{s}}{\mu}, \operatorname{Pr}=\frac{\mu C_{P, l}}{k_{l}}, \quad \mathrm{Nu}_{i}=\frac{h_{i} d_{s}^{2}}{k_{l}}, \mathrm{Ec}=\frac{u_{0}{ }^{2}}{C_{P, l}\left(T_{h}-T_{c}\right)}$, $\mathrm{Da}=\frac{h^{2}}{K}$

The CFD simulation must also consider entropy transport for a second-law analysis of the thermocline tank model. Departure from thermal equilibrium again requires separate equations for molten salt and solid filler:

$$
\begin{aligned}
& \frac{\partial\left(\rho_{l} C_{P, l} \ln \left(T_{l}\right)\right)}{\partial t}+\nabla \cdot\left(\rho_{l} \mathbf{u} C_{P, l} \ln \left(T_{l}\right)\right)=-\nabla \cdot\left(\frac{\mathbf{q}}{T_{l}}\right)+\frac{\dot{q}^{\prime \prime \prime}}{T_{l}}+\dot{S}_{g e n, l}^{\prime \prime \prime} \\
& \frac{\partial\left(\rho_{s} C_{P, s} \ln \left(T_{s}\right)\right)}{\partial t}=\frac{\dot{q}^{\prime \prime \prime}}{T_{s}}+\dot{S}_{g e n, s}^{\prime \prime \prime}
\end{aligned}
$$

Unlike the transport variables considered hitherto, entropy is not a conserved property. Thus an unknown source term $\left(\dot{S}_{g e n}^{\prime \prime \prime}\right)$ exists in both equations. This volumetric entropy generation arises from irreversible processes associated with operation of the thermocline tank, i.e., thermal diffusion and viscous dissipation. In accordance with the second law of thermodynamics, entropy generation is always non-negative.

The conservative form of the entropy transport equation is difficult to solve due to the unknown generation term. Instead, entropy transport is recast in a non-conservative form by removing conservation of mass and energy terms imbedded within Equations (11) and (12) 
(Bejan, 1986). The resultant equations are reorganized and combined into a single relation for the net entropy generation inside the porous media:

$$
\dot{S}_{\text {gen }}^{\prime \prime \prime}=\frac{k_{e f f}(\nabla T)^{2}}{T_{1}^{2}}+\frac{\mu \Phi}{T_{1}} \geq 0
$$

The complete derivation of Equation (13) is provided as an appendix.

Destruction of exergy is proportional to the generation of entropy by the following equation; the associated reference temperature $\left(T_{0}\right)$ is equal to the defined ambient temperature:

$$
\dot{X}_{\text {dest }}^{\prime \prime \prime}=T_{0} \cdot \dot{S}_{g e n}^{\prime \prime \prime}
$$

\subsection{Boundary Conditions}

To charge the thermocline tank, hot molten salt enters the top distributor port at a fixed velocity and temperature:

$$
U^{\prime}=\left(\frac{d}{d^{\prime}}\right)^{2}\left(\mathbf{u}_{h} \cdot \mathbf{e}_{z}\right) \quad T=T_{h}
$$

Simultaneous to the hot inflow, cold molten salt exits the tank via the bottom distributor. Due to transient density variations of the molten salt inside the thermocline tank, the mass and volumetric flow rate of the outflow are not known a priori.

To discharge the tank, flow is reversed such that cold molten salt enters the tank at the bottom distributor port at a fixed velocity and temperature:

$$
U^{\prime}=\left(\frac{d}{d^{\prime}}\right)^{2}\left(\mathbf{u}_{c} \cdot \mathbf{e}_{z}\right) \quad T=T_{c}
$$

The entering velocity of the cold molten salt is proportionally less than the prior hot inflow due to the increased density of the cold salt, balancing the charge and discharge processes of the thermocline tank. 
The no-slip condition is enforced at the internal wall of the tank. Thermal losses along the external wall surface are governed by forced convection associated with wind velocities:

$$
\left.k_{l} \frac{\partial T_{l}}{\partial r}\right|_{w}=h_{w}\left(T_{l}-T_{0}\right)
$$

The convection coefficient $\left(h_{w}\right)$ along the tank wall is determined using the Churchill and Bernstein (1977) correlation as a function of wind velocity and air properties at film temperature. Radiation to the environment is neglected as the tank surface is assumed to be reradiating.

\subsection{Solution Procedure}

The model fillerbed and distributor geometries are discretized into a structured nonuniform mesh, with a maximum non-dimensional cell size of $\Delta X=\Delta R=0.1$. The governing mass, momentum, and energy equations of the molten-salt are discretized with the finite-volume method and solved with the commercial computational fluid dynamics (CFD) software, FLUENT (FLUENT 12.1.4 Documentation). Spatial discretization of the internal convective fluxes is performed with a second-order upwind scheme. Transient discretization is performed with a first-order implicit formulation and a non-dimensional time step of $\Delta \tau=1.2 \times 10^{-4}$. Grid and time-step independence were previously verified by Yang and Garimella (in review). Pressure-velocity coupling is achieved with the PISO algorithm (Issa, 1986). Equation (9) for solid filler temperature and Equation (13) for fillerbed entropy generation rate are solved through user-defined functions (UDF). The solution at each time step is considered converged when all dimensionless residuals reduce to less than $10^{-4}$.

At the start of the computation, the entire thermocline tank geometry is initialized to the cold molten-salt temperature. The tank is charged with hot molten salt for 12 hours and then discharged for another 12 hours to simulate a full day of operation. It should be noted that initial isothermal condition is never realized in a physical thermocline tank. Thus successive cycling of 
the tank model is necessary to achieve the appropriate initialization. The tank then converges to a periodic temperature response with each charge and discharge process.

After convergence to periodicity, the performance of the simulated thermocline tank is measured with three efficiencies: first-law, second-law, and the ad hoc outflow temperature criterion applied by Yang and Garimella (2010a). The first- and second-law efficiencies relate the discharge of energy $(E)$ and exergy $(X)$ to the preceding charge of energy and exergy, defined as follows:

$$
\begin{gathered}
\eta_{\mathrm{I}}=\frac{E_{\mathrm{out}, \mathrm{dis}}}{E_{\mathrm{in}, \mathrm{chg}}} \\
\eta_{\mathrm{II}}=\frac{X_{\mathrm{out}, \mathrm{dis}}}{X_{\mathrm{in}, \mathrm{chg}}}
\end{gathered}
$$

In contrast, the outflow temperature criterion efficiency is defined by rejecting all molten-salt energy with a non-dimensional temperature $(\Theta)$ below 0.95 :

$$
\eta_{\mathrm{I}}=\frac{E[\Theta>0.95]_{\mathrm{out}, \mathrm{dis}}}{E_{\mathrm{in}, \mathrm{chg}}}
$$

By definition, the outflow temperature cutoff-based efficiency is always less than the first-law efficiency in Equation (16).

The energy and exergy entering the thermocline during charge are both known according to the fixed velocity boundary conditions. As previously mentioned, the characteristics of the discharge outflow are not known a priori. To assess the thermal usefulness of the molten salt leaving the tank, additional UDFs in the CFD model record the energy and exergy discharged from the tank distributor ports after every time step. The sums of the values determine the total energy and exergy delivered from the thermocline outflow. Similar UDFs monitor entropy generation inside the fillerbed. 


\section{Results and Discussion}

\subsection{Tank Sizing}

The aspect ratio of the thermocline tank geometry was reported by Yang and Garimella (2010a) to have a strong influence on the storage performance. For equal internal tank volume, tall and narrow tanks perform considerably better than short and wide tanks due to increased thermal stratification of the molten salt in the former case. For a tank of fixed height, increasing the diameter does not influence thermal stratification but only scales the maximum internal energy content of the molten salt and filler. Since the tank height is indeed constrained by the soil bearing capacity previously mentioned, thermocline tank performance optimization by aspect ratio is not practically relevant.

In the current work, the fillerbed height in the thermocline tank is fixed at $12 \mathrm{~m}$. The tank diameter is also fixed at $12 \mathrm{~m}$ (larger diameters would not provide any further insight into storage performance but would increase computation time). The thermocline tank design algorithm and efficiency model proposed by Yang and Garimella (in review) determine the molten-salt velocity for the fixed fillerbed size. Equating the non-dimensional fillerbed height $H=h /\left(u_{0} t_{0}\right)$ to the ratio of heat-exchange zone velocity to molten-salt velocity $\left(C_{0}\right)$ and fixing the effective granule diameter $\left(d_{s}\right)$ to $5 \mathrm{~cm}$, the fillerbed Reynolds number and length ratio ( $\Psi$ ) are 13.88 and 194.4, respectively. For these values, the calculated $95 \%$ outflow temperature cycle efficiency is 0.790 .

Once the fillerbed size is fixed as discussed above, the remaining parameters governing thermocline tank storage performance include the granule diameter and external losses. Yang and Garimella (2010a) found reduced granule diameter improved the thermocline performance 
by reducing the axial span of the heat-exchange region. However, analysis of the granule diameter was limited to a minimum effective diameter of $5 \mathrm{~cm}$. For the molten-salt velocity and fillerbed porosity under consideration, analysis of Darcy's law with the Kozeny-Carman equation reveals that a further reduction in granule diameter is attainable without large increases in pressure drop. Thus the simulation of the thermocline tank is extended to include smaller granule diameters of $2 \mathrm{~mm}$ and $1 \mathrm{~cm}$. (The resultant Reynolds numbers and length ratios are outside the limits of the Yang and Garimella (in review) cyclic performance model, precluding $a$ priori calculations of efficiency).

Assuming the thermocline tank is to be installed at the location of previous CSP facilities (i.e., in Barstow, CA), the local wind speeds often exceed $10 \mathrm{~m} / \mathrm{s}$ (National Climate Data Center). Thus convection may lead to substantial losses of stored energy inside the thermocline tank to the environment. Tank wall conditions associated with no losses $\left(\mathrm{Nu}_{\mathrm{w}}=0\right)$ or wind speeds of $11.1 \mathrm{~m} / \mathrm{s}(\mathrm{Nu}=4260)$ are considered to assess the influence of external convection. In conjunction with the three granule diameters of interest, a total of six thermocline cases are simulated.

As shown in Equation (13), entropy generation in the porous fillerbed is a function of both thermal diffusion and viscous dissipation. The importance of viscous dissipation $(\mu \Phi)$ with respect to fluid energy transport and entropy generation may be assessed with the nondimensional term $N$, defined as (Nield, 2000):

$$
\mathrm{N}=\frac{\mathrm{Ec} \cdot \mathrm{Pr}}{\mathrm{Da}}
$$

For porous media flows with $N$ much less than unity, viscous effects are negligible. Given the geometric scale of the thermocline tank combined with the low molten-salt velocities, the 
simulated thermocline tanks feature $N$ values on the order of $10^{-21}$. Thus viscous effects are inconsequential and omitted from the entropy generation analysis.

\subsection{Temperature and Velocity Fields}

Profiles of the molten-salt temperature along the thermocline axis during a chargedischarge operation are plotted in Figure 2 for the three adiabatic cases. As with previous studies, the reduced granule diameter $\left(d_{\mathrm{s}}=2 \mathrm{~mm}\right)$ enables a thinner heat-exchange region compared to the larger granule diameter $\left(d_{\mathrm{s}}=5 \mathrm{~cm}\right)$. At the midpoint of the charging process $(\tau=0.5)$, the heat-exchange region extends from a non-dimensional fillerbed height $(x / h)$ of 0.1 to 0.6 for the $2 \mathrm{~mm}$ granules. In contrast, this region extends from 0.1 to 0.75 for the $5 \mathrm{~cm}$ granules. Comparison of the tanks with $d_{\mathrm{s}}=2 \mathrm{~mm}$ and $d_{\mathrm{s}}=1 \mathrm{~cm}$ reveals similar lengths of the heatexchange region, implying a practical limit to thermal stratification in the dual-media mixture. The benefits of a reduced heat-exchange region for the finer fillerbed granules include greater energy content stored at the end of the charge $(\tau=1)$ as well as hotter outflow temperatures during the subsequent thermocline discharge $(1<\tau<2)$.

Temperature contours and flow streamlines in the molten salt are plotted in Figure 3 for the thermocline tank undergoing discharge $(1<\tau<2)$ with $d_{\mathrm{s}}=1 \mathrm{~cm}$. As the discharge progresses in time, hot molten salt flows out of the top distributor port until it is exhausted at the end of the cycle $(\tau=2)$. The influence of external convection $\left(\mathrm{Nu}_{\mathrm{w}}=4260\right)$ is apparent in the non-uniform flow streamlines. In the adiabatic scenario, highly organized axial velocities are sustained inside the fillerbed and result in perfect vertical stratification of the hot and cold molten salt regions (Yang and Garimella, 2010b). External convection disturbs this stratification by inducing secondary buoyancy forces in the salt cooled near the tank wall. The resultant flow reversal disrupts the streamlines by introducing radial velocities in the fillerbed, seen throughout 
the discharge process in Fig. 3. External losses also generate large vortices inside the bottom distributor, shown at $\tau=1.5$ and $\tau=2$.

\subsection{Outflow Temperature Profiles}

The outflow molten-salt temperature histories associated with tank discharge are plotted in Figure 4 for all six simulation cases. The three adiabatic cases sustain the hottest outflow temperatures throughout the discharge, expected as no stored energy is lost to the surroundings. In the non-adiabatic cases, losses to the surroundings cause small but immediate decreases in outflow temperature following the onset of tank discharge. This decline later becomes significant in the last half of the process $(\tau>1.5)$ as the heat-exchange region reaches the top distributor port. External convection reduces the internal energy content of the thermocline tank, protracting

the heat-exchange region and causing early depletion of the hot salt supply. Thus the usability of the thermocline tank for steam generation in a CSP plant decreases. As with the disruption of the temperature and velocity fields, loss of thermal quality magnifies as convection at the tank wall is increased.

Throughout most of the tank discharge, smaller granules sustain hotter outflow temperatures compared to larger granules for equivalent tank wall conditions. The thinner heatexchange region associated with the smaller granule diameter enables the presence of a larger volume of hot molten salt inside the tank, extending the duration of high-temperature outflow. However, thinner heat-exchange regions also imply larger temperature gradients which cause a more rapid decline in outflow temperature when the hot supply is exhausted. In the non-adiabatic tanks, this decline eventually leads to colder outflow temperatures for $d_{\mathrm{s}}=2 \mathrm{~mm}$ compared to $d_{\mathrm{s}}$ $=5 \mathrm{~cm}$. However, this occurs near completion of the discharge. Thus the $2 \mathrm{~mm}$ granules remain preferable for sustaining high thermal quality outflow. 


\subsection{Entropy Generation}

For a second-law perspective on the simulated thermocline tank performance, entropy generation inside the fillerbed is plotted in Figure 5 as a function of non-dimensional cycle time for $d_{\mathrm{s}}=1 \mathrm{~cm}$. Energy generation is normalized with respect to the maximum (final) value of the adiabatic cycle. As illustrated with the semi-log plot, generation is strongly influenced by the inclusion of external convection losses and results in more than an order-of-magnitude increase in generation. This trend is true for all three granule diameters. Cooling of the salt near the wall develops radial temperature gradients inside the thermocline tank, providing an additional pathway for irreversible mixing and heat transfer between the stratified hot and cold regions. The magnitude of the temperature gradient vector increases and more entropy is generated. Comparison of entropy generation between different granule diameters shows negligible variation relative to the influence of external convection.

\subsection{Thermocline Efficiency}

Thermocline tank efficiencies associated with the discharge performance are compared in Table 1 for each case. Included in the table is the first-law efficiency (ratio of energy discharged to energy charged), the second-law efficiency (ratio of exergy discharged to exergy charged), and the outflow temperature criterion-based efficiency (ratio of energy discharged with $\Theta>0.95$ to energy charged). As with the other thermocline tank metrics, tanks with adiabatic wall conditions yield the best performance for all three efficiency definitions. External losses reduce the energy and exergy content of the molten-salt discharge outflow, preventing full recovery of the energy and exergy supplied during the charge process. Reduced granule diameter also improves efficiency by sustaining more of the molten salt volume inside the tank at the hot temperature for eventual discharge. 
The second-law efficiency of the thermocline tank cycle is less than the first-law efficiency, as expected for a thermal energy storage device. This disparity remains minimal for the three adiabatic tank wall scenarios but increases with the inclusion of convection losses. As before, exergy transport accounts for not only energy but also the usability of that energy. The second-law efficiency is therefore more sensitive to the effects of convection and provides a better indication of the resultant tank performance.

Among the three metrics, energy efficiency in conjunction with a $95 \%$ outflow temperature criterion yields the lowest performance value. For the adiabatic tank with $d_{\mathrm{s}}=2 \mathrm{~mm}$, the outflow temperature remained above the $95 \%$ temperature threshold throughout the discharge, thus yielding an outflow temperature criterion-based efficiency equal to the pure first law-efficiency. For the adiabatic tank with $d_{\mathrm{s}}=5 \mathrm{~cm}$, the outflow temperature criterion-based efficiency is 0.840 . This value exceeds the efficiency predicted by the Yang and Garimella (in review) cyclic efficiency model (0.790) discussed in Section 3. It should be noted that Yang and Garimella monitored the transport of molten salt at the limits of the dual-media fillerbed, inside the distributor region. In the current investigation, tanks exposed to wind losses experience recirculation zones at this interface, adding large uncertainties to the analysis of energy and exergy exchange with the thermocline (shown in Fig. 3). The inflow and outflow of the thermocline tank are instead evaluated at the distributor ports of reduced diameter, where recirculation does not occur, to avoid this uncertainty. Inclusion of the distributer regions effectively increases the height of the tank and results in a thermocline cycle efficiency greater than the model prediction.

As with the second-law efficiency, the outflow temperature criterion-based efficiency is subject to large decreases for non-adiabatic tanks. External losses generate small but immediate 
drops in outflow temperature at the star of discharge, as seen in Fig. 4. This temperature drop off inhibits sustained delivery of hot molten salt with $\Theta>0.95$, resulting in temperature-criterion efficiencies as low as 0.426 . Because of this sharp decline compared to the previous first- and second-law efficiency definitions, the $\Theta>0.95$ stipulation for molten salt outflow is an overly conservative thermocline tank design metric. As indicated by the second-law efficiency, moltensalt outflow below this temperature remains serviceable for the power block. Instead of rejecting this colder outflow, the Rankine cycle should be compliant with the lower-quality molten salt to continue steam generation and power output at reduced thermal efficiency. A practical example of this capability is the power block within SEGS VI parabolic trough plant, which can operate with the HTF being as much as $90 \mathrm{~K}$ below the nominal design point (Kolb, 2011).

\section{Conclusions}

Thermocline tanks are a low-cost thermal energy storage option for large-scale CSP plants. Numerical simulation of a dual-media thermocline tank is performed to investigate the effects of different granule diameters and non-adiabatic boundary conditions along the tank wall. Performance of the thermocline tank is assessed with three separate metrics: outflow temperature with discharge time, entropy generation inside the fillerbed, and net cycle efficiency. Efficiency of the tank is measured in terms of molten-salt energy, exergy, as well as energy subject to an outflow temperature criterion.

Thermocline tanks filled with small granules exhibit narrower heat-exchange regions relative to tanks with large granules. This improves the thermal stratification of the molten salt and yields higher outflow temperatures during discharge. The thermocline efficiency (both firstand second-law) is consequently greater for the smaller granule diameter. However, a trade-off 
exists between thermocline performance and increased pumping power to overcome the reduced fillerbed permeability. An economic and experimental study is recommended to optimize granule diameter between storage efficiency and pressure drop.

Entropy generation inside the fillerbed is predominantly a function of the thermal boundary conditions at the tank wall. The presence of external convection introduces radial temperature gradients, leading to increased irreversible thermal diffusion and greater entropy generation. External convection also reduces the thermocline tank efficiency due to the loss of hot molten salt available for discharge. This reduction is most severe in the outflow temperature criterion-based efficiency, but this is demonstrated to be an overly conservative performance metric. Determination of both the first and second-law tank efficiency eliminates the need for ad hoc thermal analysis. Combining this analysis with a power block model will complement these model efficiencies and increase practical understanding by relating the outflow temperature degradation during discharge to CSP plant performance.

\section{Acknowledgement}

The authors would like to thank Professor Zhen Yang of Tsinghua University for helpful discussions related to evaluation of thermocline cycle efficiency. 


\section{References}

Beckermann C., Viskanta, R., 1988. Natural convection solid/liquid phase change in porous media. Int. J. Heat Mass Transfer 31, 35-46.

Bejan, A., 1984. Convection Heat Transfer. John Wiley \& Sons, Hoboken, New Jersey.

Bejan, A., 2006. Advanced Engineering Thermodynamics, $3^{\text {rd }}$ Ed. John Wiley \& Sons, Hoboken, New Jersey.

Churchill, S.W., Bernstein, M., 1977. A correlating equation for forced convection from gases and liquids to a circular cylinder in crossflow. J. Heat Transfer 99, 300-306.

Electric Power Research Institute. Solar Thermocline Storage Systems: Preliminary Design Study. Palo Alto, CA: 2010. 1019581.

Evans, L.C., 2004. Entropy and partial differential equations. http://math.berkeley.edu/ evans/entropy.and.PDE.pdf, last accessed October 2011.

Faas, S.E., Thorne, L.R., Fuchs, E.A., Gilbertsen, N.D., 1986. 10 MWe solar thermal central receiver pilot plant: thermal storage system evaluation - final report. Sandia National Laboratories Report, SAND86-8212.

Flueckiger, S., Yang, Z., Garimella, S.V., 2011. An integrated and mechanical investigation of molten-salt thermocline energy storage. Appl. Energy 88, 2098-2105.

FLUENT 12.1.4 Documentation, Fluent Inc.

Gonzo, E.E., 2002. Estimating correlations for the effective thermal conductivity of granular materials. J. Chem. Eng. 90, 299-302.

Heraeus Base Materials. http://www.semiquarz.ed/pdf/hereausbasematerial.pdf, last accessed October 2011.

Herrmann, U., Kearney, D.W., 2002. Survey of thermal energy storage for parabolic trough power plants. J. Sol. Energy Eng. 124, 145-152. 
HITEC Heat Transfer Salt. Coastal Chemical Co., L.L.C., Brenntag Company, 2011. http://www.coastalchem.com/, last accessed on October 2011.

Issa, R.I., 1986. Solution of implicitly discretized fluid flow equations by operator splitting. J. Comput. Phys. 62, 40-65.

Kearney, D.W., Herrmann, U., Nava, P., Kelly, B., Mahoney, R., Pacheco, J., Cable, R., Potrovitza, N., Blake, D., Price, H., 2003. Assessment of a molten salt heat transfer fluid in a parabolic trough solar field. J. Sol. Energy Eng. 125, 170-176.

Kolb, G.J., Alpert, D.J., Lopez, C.W., 1991. Insights from the operation of Solar One and their implications for future central receiver plants. Sol. Energy 47, 39-47.

Kolb, G.J., 2006. Performance analysis of thermocline energy storage. ISEC2006-99005. Proceedings of the ASME International Solar Energy Conference, Denver, Colorado.

Kolb, G.J., 2011. Evaluation of annual performance of 2-tank and thermocline thermal storage systems for trough plants. J. Sol. Energy Eng. 133, 031023-1.

Krishnan, S., Murthy, J.Y., Garimella, S.V., 2004. A two-temperature model for analysis of passive thermal control systems. J. Heat Transfer 126, 628-637.

Lovegrove, K., Luzzi, A., Soldiani, I., Kreetz, H., 2004. Developing ammonia based thermochemical energy storage for dish power plants. Sol. Energy 76, 331-337.

Mills, D.R., Morrison, G.L., 2000. Compact linear Fresnel reflector solar thermal powerplants. Sol. Energy 68, 263-283.

National Climate Data Center, National Oceanic and Atmospheric Administration, 2011. http://www4.ncdc.noaa.gov/cgi-win/wwcgi.dll?wwevent storms, last accessed October 2011. 
Nield, D.A., 2000. Resolution of a paradox involving viscous dissipation and non-linear drag in a porous medium. Transport Porous Media 41, 349-357.

Pacheco, J.E., Showalter, S.K., Kolb, W.J., 2002. Development of a molten salt thermocline thermal storage system for parabolic trough plants. J. Sol. Energy Eng. 124, 153-159.

Radosevich, L.G., 1988. Final report on the power production phase of the $10 \mathrm{MWe}$ solar thermal central receiver pilot plant. Sandia National Laboratories Report, SAND87-8022.

Specific Heat Capacities of Some Common Substances. The Engineering Toolbox, http://www.engineeringtoolbox.com/specific-heat-capacity-d_391.html, last accessed October 2011.

Wakao, N., Kaguei, S., 1982. Heat and Mass Transfer in Packed Beds. Gordon and Beach, New York.

Yang, Z., Garimella, S.V., 2010. Thermal analysis of solar thermal energy storage in a moltensalt thermocline. Sol. Energy 84, 974-985.

Yang, Z., Garimella, S.V., 2010. Molten-salt thermal energy storage in thermoclines under different environmental boundary conditions. Appl. Energy 87, 3322-3329.

Yang, Z., Garimella, S.V. Cyclic operation of molten-salt thermal energy storage in thermoclines for solar power plants. Energy Conv. Mgmt, in review. 


\section{Appendix - Entropy generation in an unconsolidated porous medium}

In accordance with the second law of thermodynamics, entropy transport in a differential control volume is governed by the following equation:

$$
\frac{\partial(\rho s)}{\partial t}+\nabla \cdot(\rho \mathbf{u} s)=-\nabla \cdot\left(\frac{\mathbf{q}}{T}\right)+\frac{\dot{q}^{\prime \prime \prime}}{T}+\dot{S}_{g e n}^{\prime \prime \prime}
$$

The transport equation is recast in non-conservative form by formulating the transient and convection terms as a material derivative of entropy. Equation (A1) is reorganized to solve for the volumetric entropy generation (Bejan, 1986; Evans, 2004):

$$
\dot{S}_{g e n}^{\prime \prime \prime}=\rho \frac{D s}{D t}+\nabla \cdot\left(\frac{\mathbf{q}}{T}\right)-\frac{\dot{q}^{\prime \prime \prime}}{T}
$$

For incompressible materials, the above material derivative converts to a material derivative of temperature. The divergence of the heat flux over temperature is also expanded to give:

$$
\dot{S}_{g e n}^{\prime \prime \prime}=\rho \frac{C_{P}}{T} \frac{D T}{D t}+\frac{\nabla \cdot \mathbf{q}}{T}-\frac{\mathbf{q} \cdot \nabla T}{T^{2}}-\frac{\dot{q}^{\prime \prime \prime}}{T}
$$

For a porous medium, separate entropy generation equations must be considered for the liquid and solid phases. In the case of a molten-salt thermocline, the solid filler is granular or unconsolidated. Due to contact resistance between particles, thermal diffusion is neglected in the solid equation. The solid region still contributes to thermal diffusion in the liquid region through an effective thermal conductivity (Gonzo, 2002). The energy source term in both equations represents convective heat exchange between the liquid and the filler:

$$
\begin{aligned}
& \dot{S}_{g e n, l}^{\prime \prime \prime}=\varepsilon \rho_{l} \frac{C_{P, l}}{T_{l}} \frac{D T_{l}}{D t}+\frac{\nabla \cdot \mathbf{q}}{T_{l}}-\frac{\mathbf{q} \cdot \nabla T_{l}}{T_{l}^{2}}-\frac{h_{i}\left(T_{s}-T_{l}\right)}{T_{l}} \\
& \dot{S}_{g e n, s}^{\prime \prime \prime}=(1-\varepsilon) \rho_{s} \frac{C_{P, s}}{T_{s}} \frac{D T_{s}}{D t}+\frac{h_{i}\left(T_{s}-T_{l}\right)}{T_{s}}
\end{aligned}
$$


To further simplify the resultant entropy equations, the energy transport equations below are reconsidered:

$$
\begin{aligned}
& \frac{\partial\left(\varepsilon \rho_{l} C_{P, l} T_{l}\right)}{\partial t}+\nabla \cdot\left(\rho_{l} \mathbf{u} C_{P, l} T_{l}\right)=-\nabla \cdot \mathbf{q}+\mu \Phi+h_{i}\left(T_{s}-T_{l}\right) \\
& \frac{\partial\left((1-\varepsilon) \rho_{s} C_{P, l}\right)}{\partial t}=-h_{i}\left(T_{s}-T_{l}\right)
\end{aligned}
$$

As with entropy transport, the fluid energy transport equation is recast in non-conservative form to generate a material derivative of enthalpy. As an incompressible fluid, this material derivative is again converted to a material derivative of temperature.

$$
\begin{aligned}
& \varepsilon \rho_{l} C_{P, l} \frac{D T_{l}}{D t}=-\nabla \cdot \mathbf{q}+\mu \Phi+h_{i}\left(T_{s}-T_{l}\right) \\
& (1-\varepsilon) \rho_{s} C_{P, s} \frac{\partial T_{s}}{\partial t}=-h_{i}\left(T_{s}-T_{l}\right)
\end{aligned}
$$

The resultant energy equations are incorporated into the previous entropy equations, shown below:

$$
\begin{aligned}
& \dot{S}_{g e n, l}^{\prime \prime \prime}=-\frac{\mathbf{q} \cdot \nabla T_{l}}{T_{l}^{2}}+\frac{\mu \Phi}{T_{l}} \\
& \dot{S}_{g e n, s}^{\prime \prime \prime}=0
\end{aligned}
$$

In the liquid region, the result is simply the dot product of the heat flux and temperature gradient over the temperature squared plus the effects of viscous dissipation. In contrast, the solid region is revealed to be isentropic. This result is an artifact of the model assumption that thermal diffusion between the solid granules is negligible. Thus the net volumetric entropy generation in an unconsolidated porous medium is governed by the following:

$$
\dot{S}_{g e n}^{\prime \prime \prime}=\frac{k_{e f f}\left(\nabla T_{l}\right)^{2}}{T_{l}^{2}}+\frac{\mu \Phi}{T_{l}} \geq 0
$$


It should be noted that the derivation of Equation (A12) did not require any assumptions related to the material properties of the liquid region. Functional dependencies on temperature (inherent to the liquid molten salt) are effectively removed by mass and energy conservation. 


\section{Nomenclature}

$C_{P} \quad$ specific heat, $\mathrm{J} / \mathrm{kg} \mathrm{K}$

$d \quad$ diameter of thermocline tank, $\mathrm{m}$

d' diameter of inlet and outlet ports, $\mathrm{m}$

$d_{\mathrm{s}} \quad$ diameter of filler granules, $\mathrm{m}$

$\mathbf{e}_{\mathbf{r}} \quad$ unit vector in the r-direction, -

$\mathbf{e}_{\boldsymbol{\theta}} \quad$ unit vector in the $\theta$-direction, -

$\mathbf{e}_{\mathbf{x}} \quad$ unit vector in the $\mathrm{x}$-direction, -

$E \quad$ energy (enthalpy), $\mathrm{J}$

F inertial coefficient, -

$h \quad$ height of thermocline fillerbed, $\mathrm{m}$

$h$ height of tank distributors, $\mathrm{m}$

$h_{\mathrm{i}} \quad$ interstitial convection coefficient, $\mathrm{W} / \mathrm{m}^{3} \mathrm{~K}$

$h_{\mathrm{w}} \quad$ external convection coefficient, $\mathrm{W} / \mathrm{m}^{2} \mathrm{~K}$

$k \quad$ thermal conductivity, $\mathrm{W} / \mathrm{m} \mathrm{K}$

$K \quad$ permeability, $\mathrm{m}^{2}$

$r \quad$ radial tank location, $\mathrm{m}$

$S \quad$ entropy, J/K

$S_{\text {gen }}$ entropy generation, J/K

$t_{0} \quad$ half-cycle period, $\mathrm{s}$ 


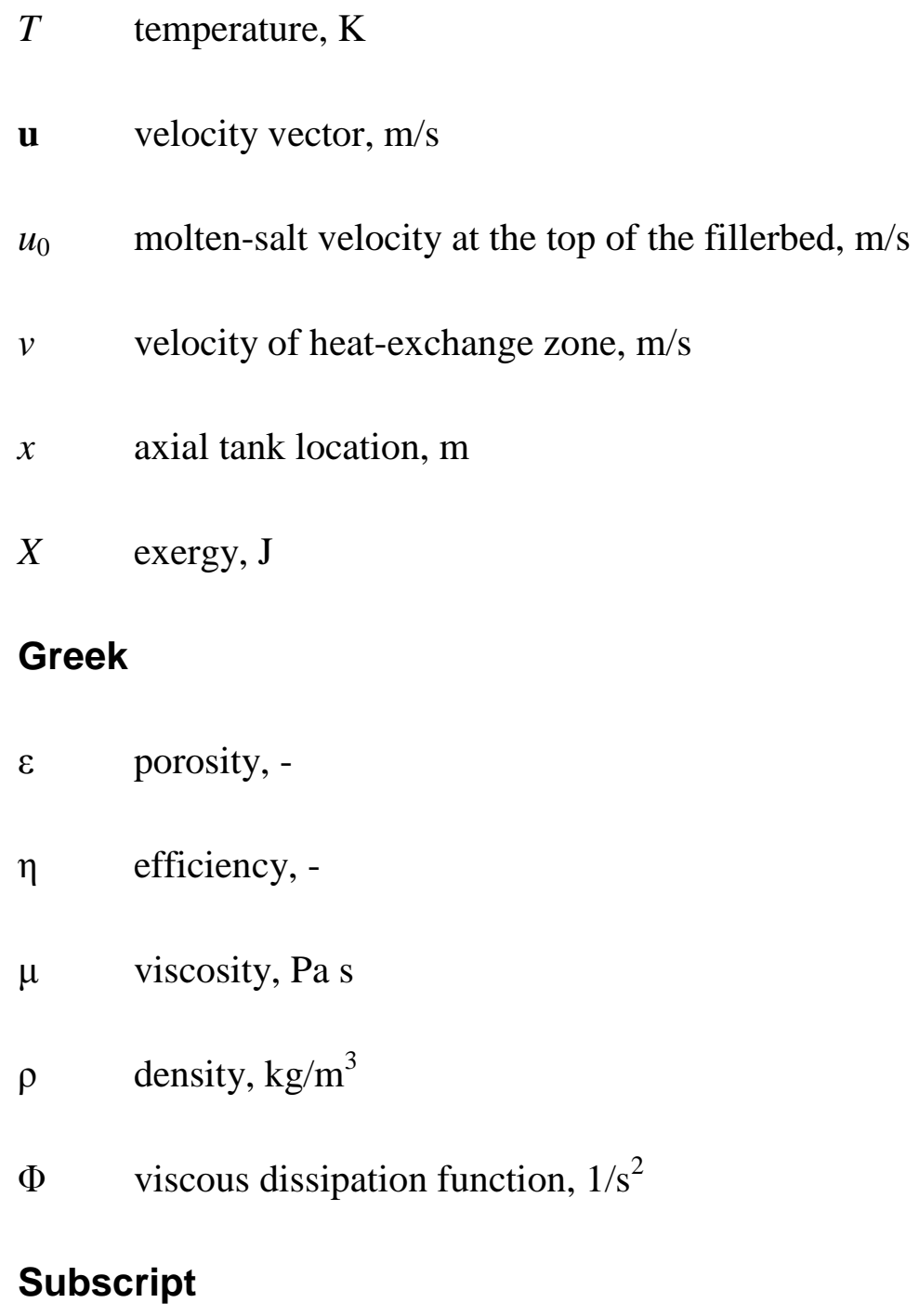


second law 


\section{Table}

Table 1 Summary of thermocline tank efficiencies (first law, second law, and temperature criterion) for different external loss conditions $\left(\mathrm{Nu}_{\mathrm{w}}\right)$ and granule diameter $\left(d_{\mathrm{s}}\right)$.

\begin{tabular}{cccccc}
\hline Case & $d_{\mathrm{S}}[\mathrm{cm}]$ & $\mathrm{Nu}_{\mathrm{w}}$ & $\eta_{\mathrm{I}}$ & $\eta_{\mathrm{II}}$ & $\eta_{\mathrm{I}, 95}$ \\
\hline 1 & 0.2 & 0 & 0.975 & 0.975 & 0.975 \\
2 & 0.2 & 4260 & 0.940 & 0.923 & 0.748 \\
3 & 1 & 0 & 0.975 & 0.974 & 0.964 \\
4 & 1 & 4260 & 0.921 & 0.893 & 0.597 \\
5 & 5 & 0 & 0.966 & 0.961 & 0.840 \\
6 & 5 & 4260 & 0.903 & 0.868 & 0.426 \\
\hline
\end{tabular}




\section{List of Figures}

Figure 1 Schematic illustration of a thermocline tank thermal energy storage system.

Figure 2 Molten-salt temperatures along axis of an adiabatic thermocline tank during a chargedischarge cycle for different granule diameter: (a) $d_{\mathrm{s}}=2 \mathrm{~mm}$, (b) $d_{\mathrm{s}}=1 \mathrm{~cm}$, (c) $d_{\mathrm{s}}=5$ $\mathrm{cm}$.

Figure 3 Molten-salt temperature contours and velocity fields of a thermocline tank during the discharge process in the presence of external convection $\left(\mathrm{Nu}_{\mathrm{w}}=4260\right)$ at the tank wall. The fillerbed region extends from 0 to 1 along the non-dimensional tank height and is composed of $1 \mathrm{~cm}$ granules.

Figure 4 Outflow temperature history of thermocline tank discharge for different tank wall conditions and granule diameter.

Figure 5 History of entropy generation inside thermocline tank fillerbed during a chargedischarge cycle for adiabatic and external loss conditions $\left(d_{\mathrm{s}}=1 \mathrm{~cm}\right)$. 


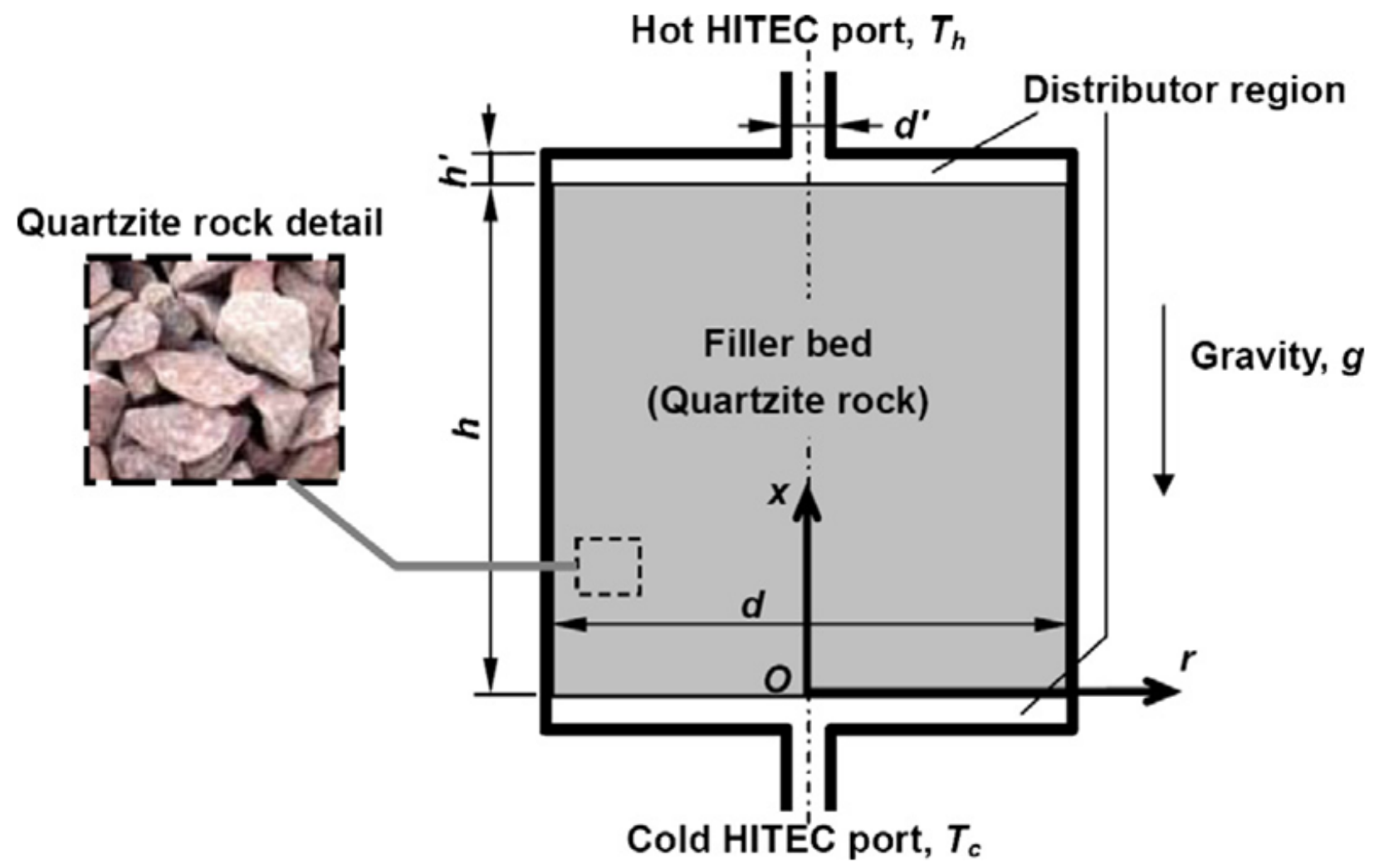

Figure 1 Schematic illustration of a thermocline tank thermal energy storage system. 


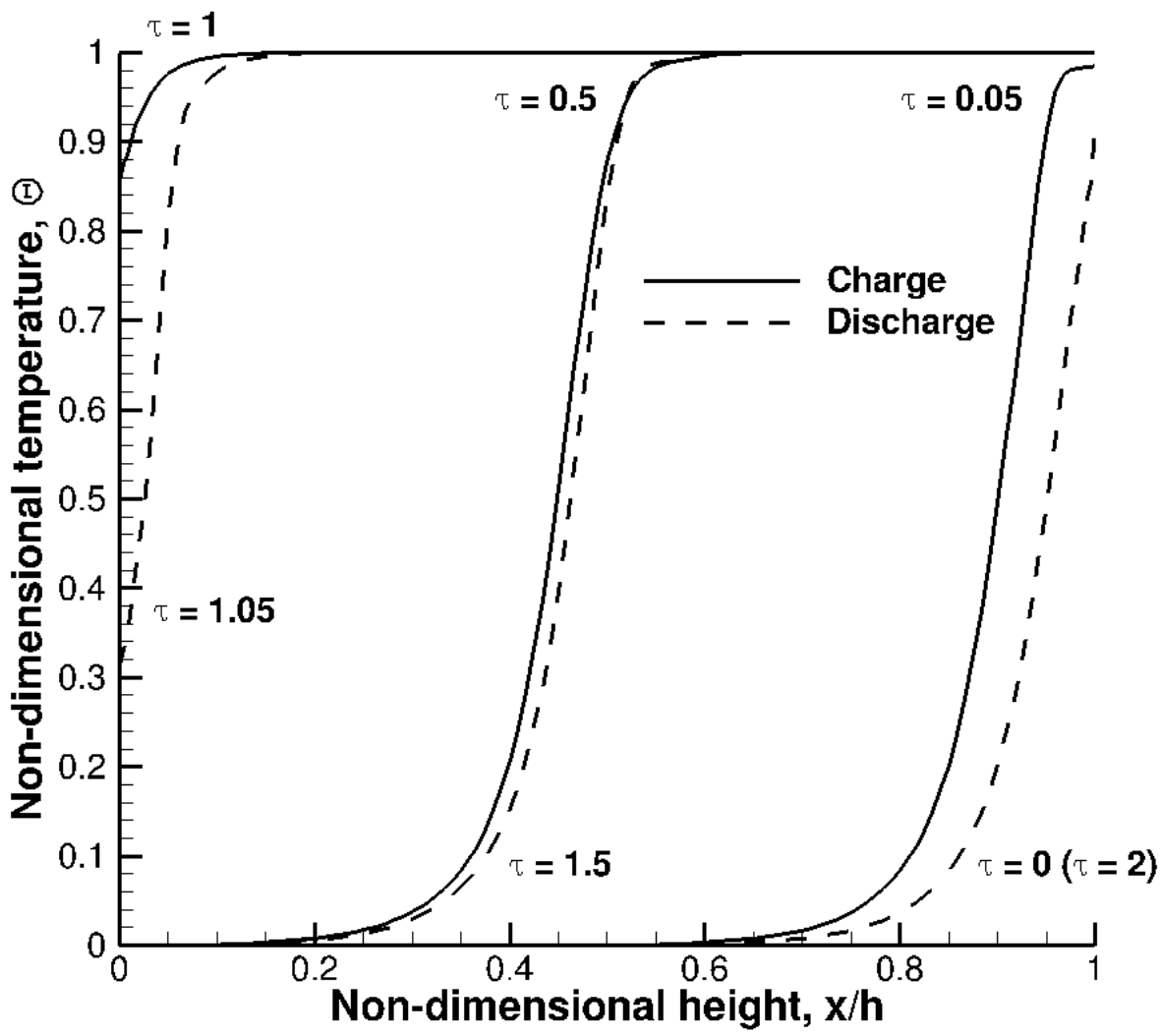

(a) 


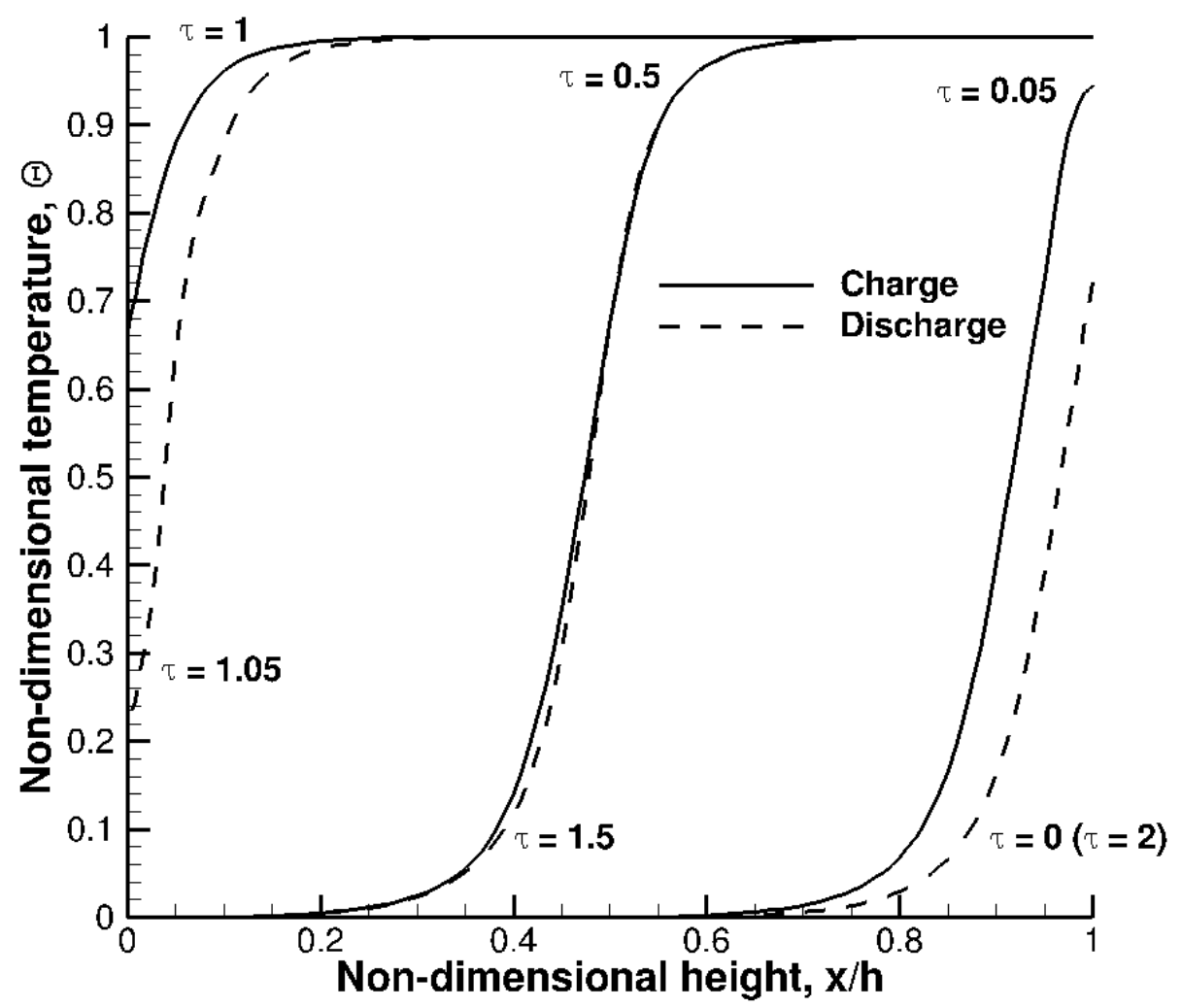

(b) 


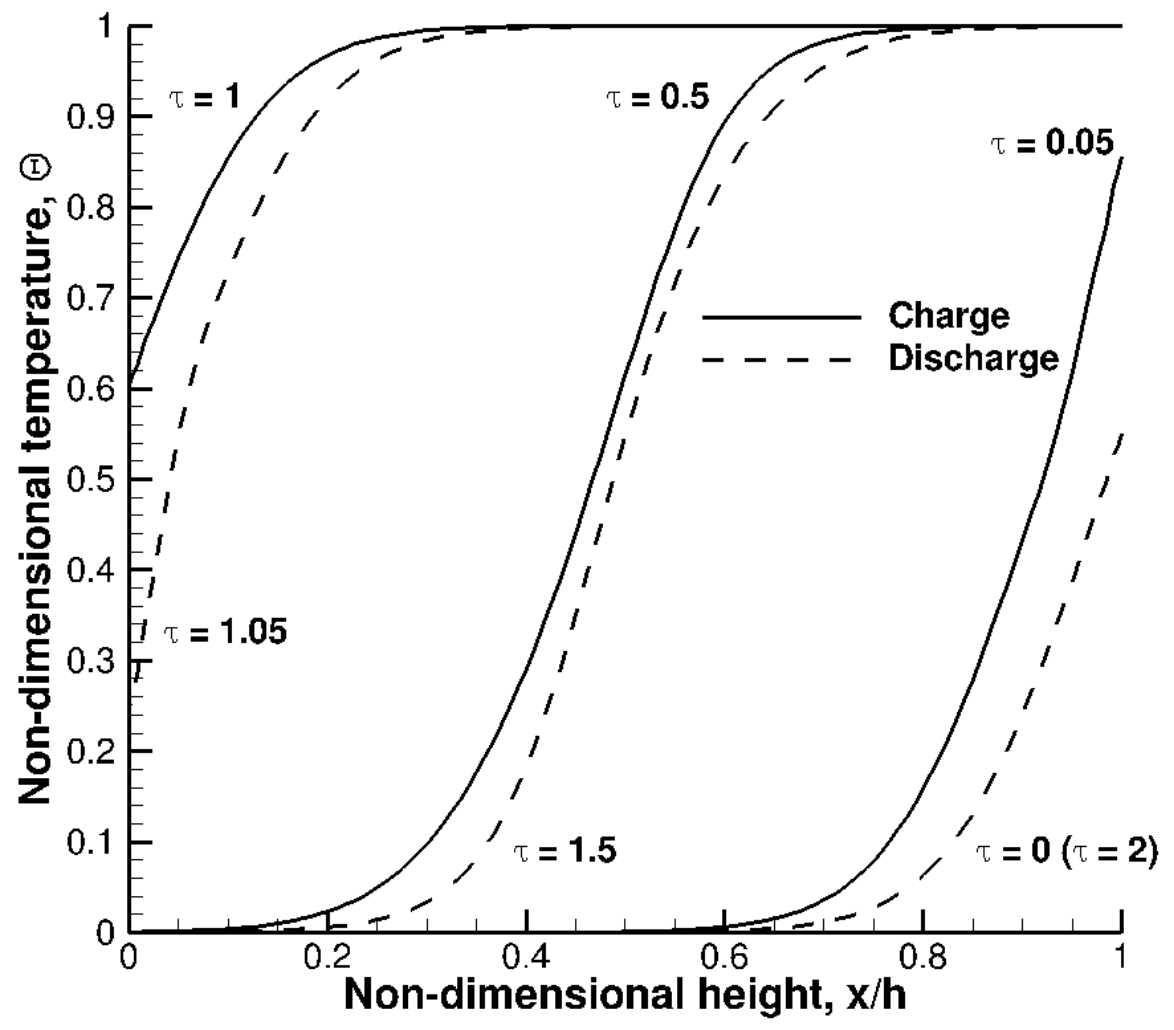

(c)

Figure 2 Molten-salt temperatures along axis of an adiabatic thermocline tank during a chargedischarge cycle for different granule diameter: (a) $d_{\mathrm{s}}=2 \mathrm{~mm}$, (b) $d_{\mathrm{s}}=1 \mathrm{~cm}$, (c) $d_{\mathrm{s}}=5 \mathrm{~cm}$. 


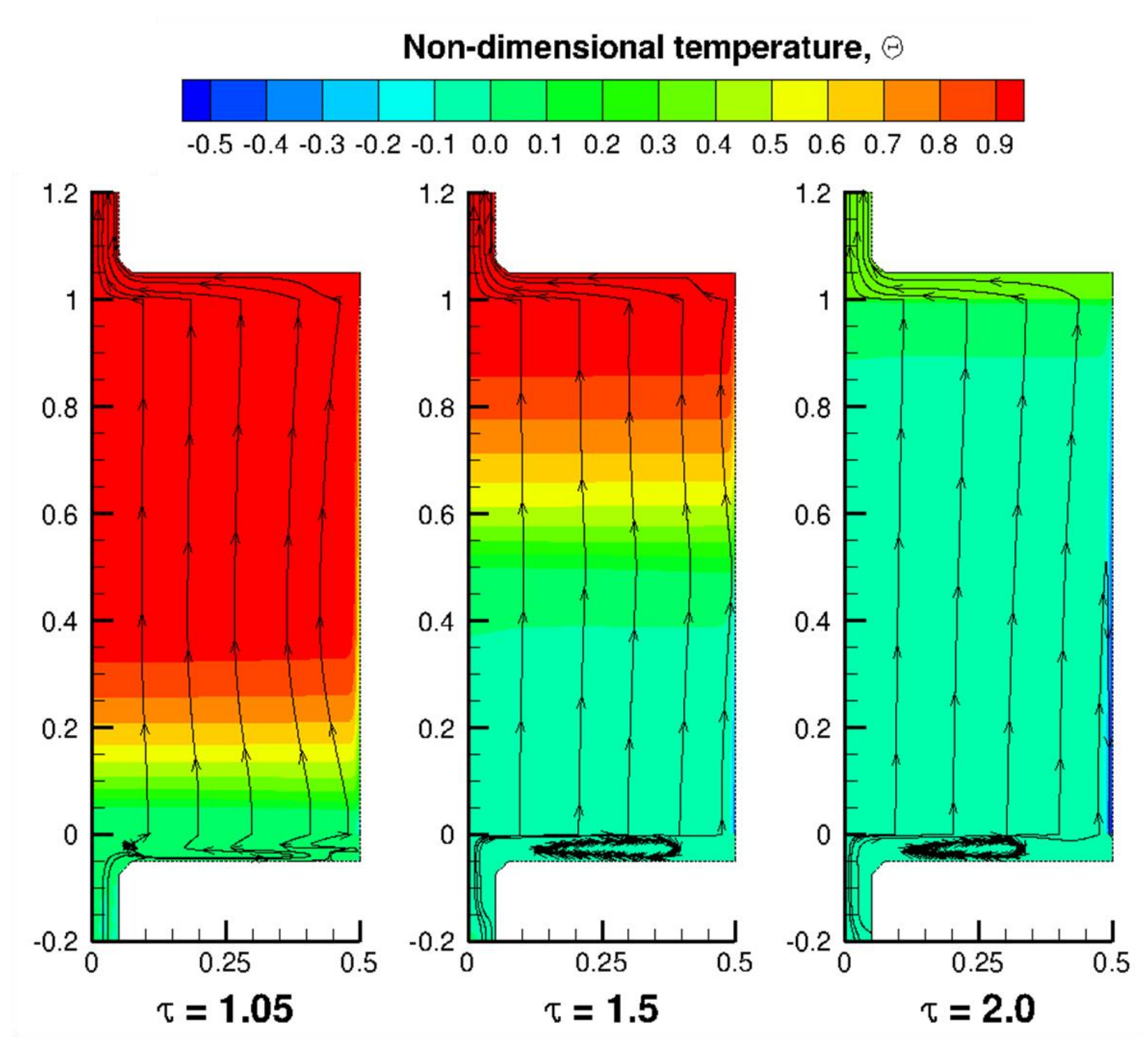

Figure 3 Molten-salt temperature contours and velocity fields of a thermocline tank during the discharge process in the presence of external convection $\left(\mathrm{Nu}_{\mathrm{w}}=4260\right)$ at the tank wall. The fillerbed region extends from 0 to 1 along the non-dimensional tank height and is composed of 1 cm granules. 


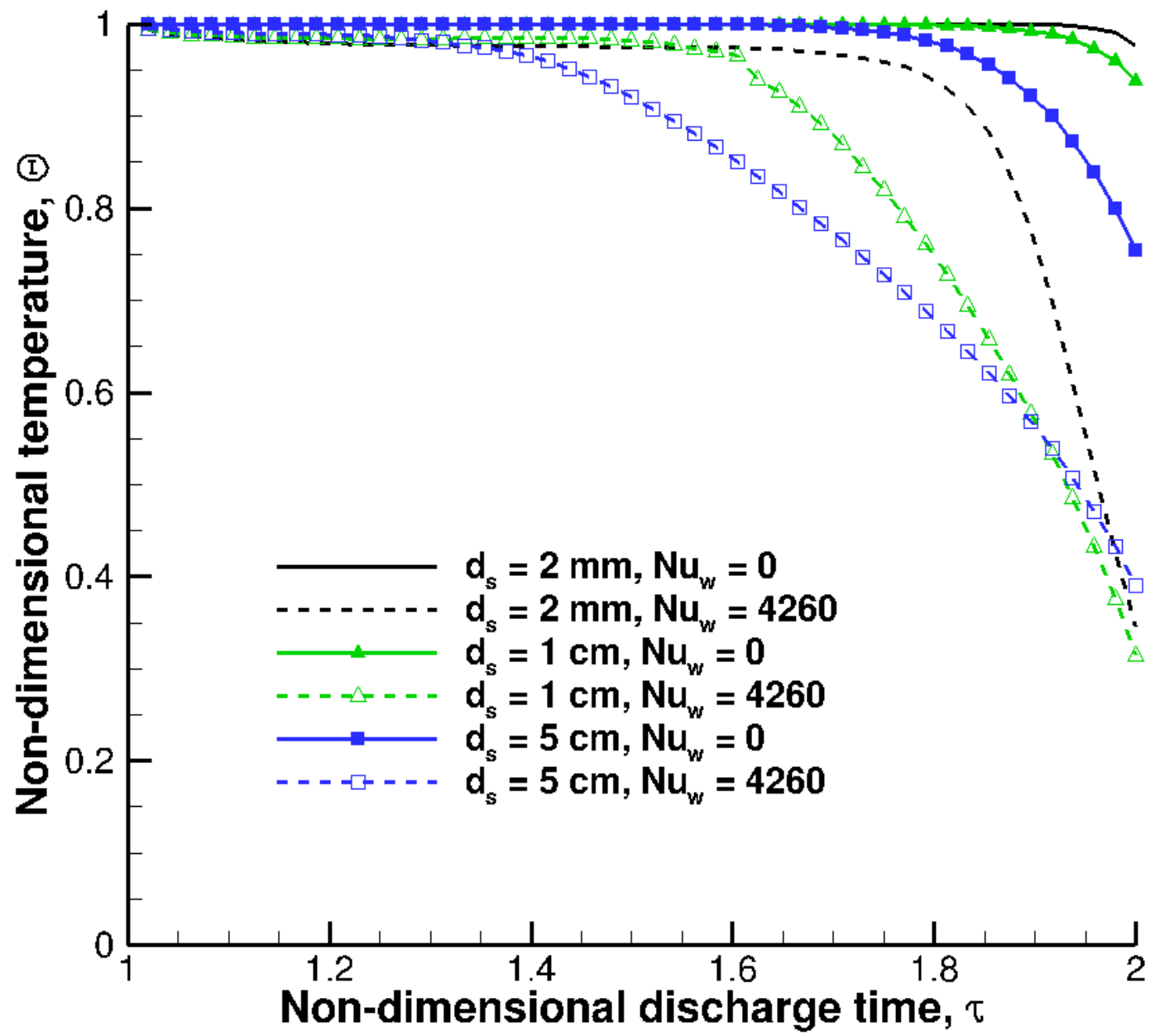

Figure 4 Outflow temperature history of thermocline tank discharge for different tank wall conditions and granule diameter. 


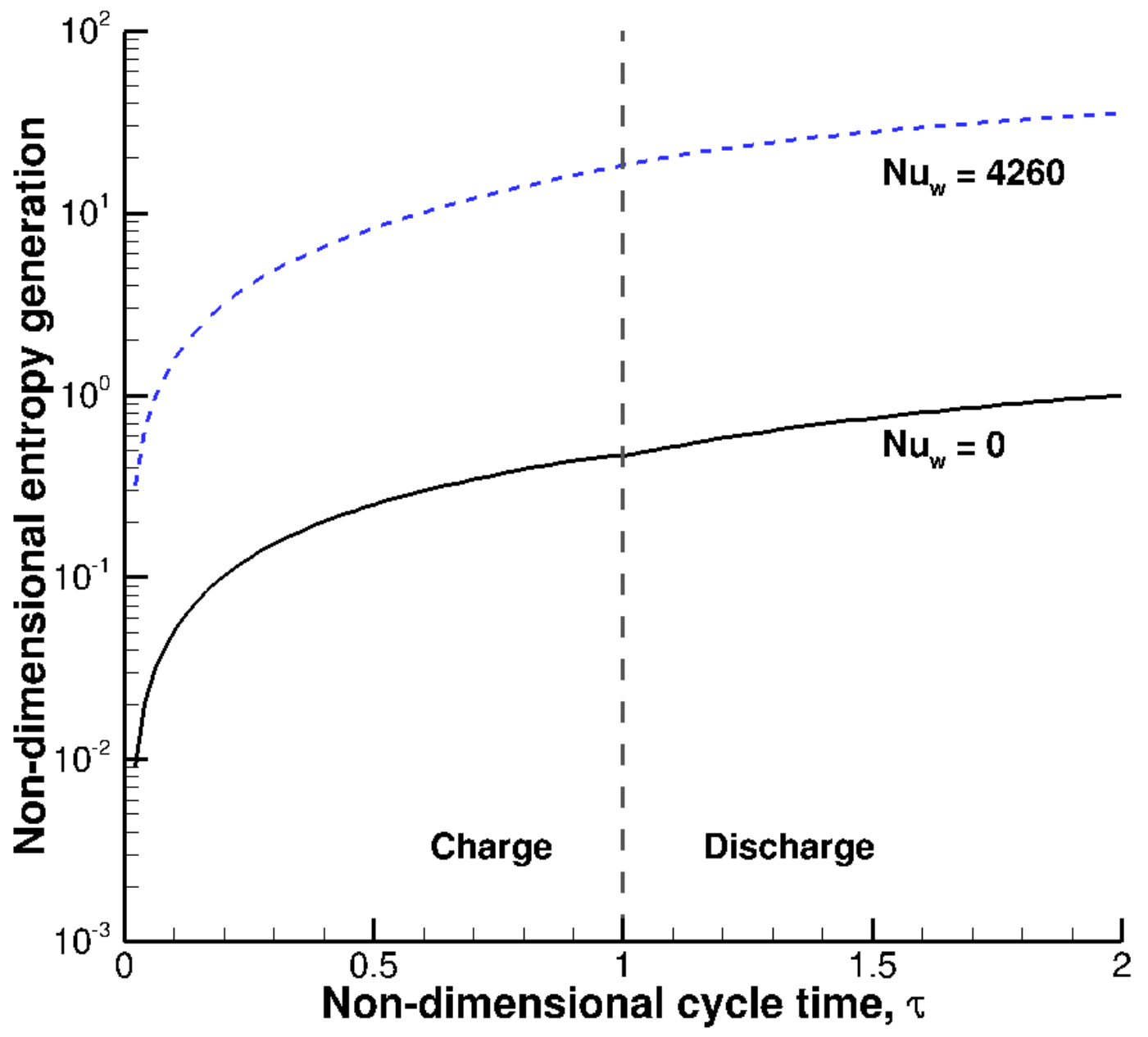

Figure 5 History of entropy generation inside thermocline tank fillerbed during a chargedischarge cycle for adiabatic and external loss conditions $\left(d_{\mathrm{s}}=1 \mathrm{~cm}\right)$. 